Case Report

\title{
Conservative Technique Using Oral Dressing Material for Wound Dehiscence after Ridge Augmentation: A Technical Report with a Case Series
}

\author{
Jeong-Kui Ku ${ }^{1,+} \mathbb{D}$, Yeong Kon Jeong ${ }^{2,+}$, Yong-Suk Choi ${ }^{2}$, Taeyeong Kim ${ }^{3} \mathbb{D}$, In-Woo Cho ${ }^{4}$ and \\ Dae Ho Leem ${ }^{5,6, *}$ \\ 1 Department of Oral and Maxillofacial Surgery, Gangnam Severance Hospital, Yonsei University College \\ of Dentistry, Seoul 06273, Korea; kujk@yuhs.ac \\ 2 Department of Oral and Maxillofacial Surgery, Section of Dentistry, Armed Forces Capital Hospital, \\ Seongnam 13574, Korea; ykjung5111@hanmail.net (Y.K.J.); cys2c@hanmail.net (Y.-S.C.) \\ 3 Department of Pathology, Armed Forces Capital Hospital, Seongnam 13574, Korea; wsckty@gmail.com \\ 4 Department of Periodontology, College of Dentistry, Dankook University, Cheonan 31115, Korea; \\ sinuslift@hanmail.net \\ 5 Department of Oral and Maxillofacial Surgery, School of Dentistry, Jeonbuk National University, \\ Jeonju 54896, Korea \\ 6 Research Institute of Clinical Medicine, Jeonbuk National University-Biomedical Research Institute, \\ Jeonbuk National University Hospital, Jeonju 54896, Korea \\ * Correspondence: idisho@jbnu.ac.kr; Tel.: +82-63-250-2113; Fax: +82-63-250-2089 \\ + These authors contributed equally to this work.
}

check for

updates

Citation: Ku, J.-K.; Jeong, Y.K.; Choi, Y.-S.; Kim, T.; Cho, I.-W.; Leem, D.H. Conservative Technique Using Oral Dressing Material for Wound Dehiscence after Ridge Augmentation: A Technical Report with a Case Series. Appl. Sci. 2021, 11, 6115. https://doi.org/10.3390/ app11136115

Academic Editor: Francesca Silvagno

Received: 11 May 2021

Accepted: 28 June 2021

Published: 30 June 2021

Publisher's Note: MDPI stays neutral with regard to jurisdictional claims in published maps and institutional affiliations.

Copyright: (c) 2021 by the authors. Licensee MDPI, Basel, Switzerland. This article is an open access article distributed under the terms and conditions of the Creative Commons Attribution (CC BY) license (https:// creativecommons.org/licenses/by/ $4.0 /)$.

\begin{abstract}
Wound dehiscence is the most frequent complication after ridge augmentation and causes postoperative infection, inadequate bone healing, or graft failure. In the oral cavity, conservative treatment for dehiscence is difficult to maintain until secondary healing occurs because of its normal flora, dynamic masticatory muscle movement, and humid environment. This paper reports an effective conservative method using an oral wound dressing material with an omnivec splint and presents three wound dehiscence cases: (1) autogenous tooth bone graft material with a collagen membrane, with dehiscence occurring at postoperative 5 days. (2) Autogenous bone graft covering titanium mesh, with dehiscence occurring at postoperative three weeks. The mesh was removed after 10 weeks with histologic analysis. (3) Autogenous bone and autogenous tooth bone graft covering a titanium mesh, with dehiscence occurring at postoperative 1 week. The exposed titanium mesh was maintained for 6 months after the graft. All cases achieved secondary healing and acceptable outcomes for a dental implant by conservative treatment without infection after the dehiscence after ridge augmentation.
\end{abstract}

Keywords: alveolar ridge augmentation; bone regeneration; complications; conservative treatment; surgical wound dehiscence; titanium

\section{Introduction}

The reconstruction of severe atrophy or defects on the alveolar bone resulting from a pathologic lesion is a clinically challenging indication for ridge augmentation [1]. High osteogenic potency bone substrates have been used for the severe defects, such as autogenous bone and demineralized dentin matrix with rhBMP-2 (Auto-DDM/rhBMP-2, Korea Tooth Bank, Korea) [2,3]. The common complication of the ridge augmentation is wound dehiscence, which is caused mainly by a lack of soft tissue and tension of the flap [1,4]. The exposed grafts could be contaminated, leading to infection and the loss of grafted bone [4]. On the other hand, the earlier intervention, such as membrane removal or re-suture, can adversely affect graft stability [5]. For sufficient bone healing, graft stability should be secured during the vascularization and remodeling period. 
Several dressing materials have been developed for the oral cavity, which is an unfavorable condition, including humidity, normal flora, dynamic muscle movement, and divided into the three categories: (1) zinc oxide and eugenol, (2) zinc oxide without eugenol, and (3) neither zinc oxide nor eugenol [6]. An effective dressing should have a short setting time, antibacterial ability, and high adhesion and retention properties. With eugenol, however, the dressing material can cause tissue inflammation and allergic reactions [7]. Zinc oxide without eugenol has been used widely as a periodontal dressing owing to its high mechanical strength and retention property. On the other hand, the mechanical property prevents application by the patient and maintenance oral hygiene from plaque accumulation. To overcome these disadvantages, neither zinc oxide nor eugenol was developed as an attachable band-type dressing material with enhanced availability, and is composed of mainly with ethyl cellulose and two surfaces: adhesion surface (tocopherol acetate, Carbomer 940 and hydroxyethyl cellulose) toward the gingiva, and protective surface (ethyl cellulose and castor oil) with a film form. On the other hand, its repetitive application on the exact surgical area to block bacterial invasion is difficult for the patients to perform themselves.

An ideal conservative treatment has not been established to maintain proper oral hygiene and allow secondary healing on the wound dehiscence after ridge augmentation. This case series suggests an effective conservative method using an oral wound dressing material with an omnivec splint and presents three cases for the wound dehiscence after ridge augmentation.

\section{Materials and Methods}

The case series was approved and granted an exemption in writing by the Institutional Review Board at Armed Forces Capital Hospital (No. AFCH-20-IRB-041). Table 1 lists the cases.

Table 1. Summary of the wound dehiscence cases with conservative treatment.

\begin{tabular}{|c|c|c|c|c|}
\hline Case & $\begin{array}{c}\text { Sex } \\
\text { (Age, Year) }\end{array}$ & Bone Graft Surgery & $\begin{array}{l}\text { Timing of Wound } \\
\text { Dehiscence }\end{array}$ & Postoperative Treatment \\
\hline 1 & $\begin{array}{c}\text { Male } \\
(42)\end{array}$ & $\begin{array}{l}\text { Implant placement } \\
\text { and DDM/rhBMP-2 } \\
\text { graft with Ossguide }\end{array}$ & Five days & $\begin{array}{l}\text { 1. Orascar with omnivac splint for } 3 \text { weeks } \\
\text { 2. Prosthetic loading at } 6 \text { months after the surgery }\end{array}$ \\
\hline 2 & $\begin{array}{c}\text { Male } \\
(42)\end{array}$ & $\begin{array}{l}\text { Autogenous bone } \\
\text { graft with Retro } \\
\text { Ti-matrix }\end{array}$ & Three weeks & $\begin{array}{l}\text { 1. Orascar with omnivac splint for two weeks } \\
\text { 2. Mesh removal and biopsy at } 10 \text { weeks after the } \\
\text { surgery }\end{array}$ \\
\hline 3 & $\begin{array}{c}\text { Male } \\
(24)\end{array}$ & $\begin{array}{l}\text { Autogenous bone } \\
\text { and DDM/rhBMP-2 } \\
\text { graft with Retro } \\
\text { Ti-matrix }\end{array}$ & Seven days & $\begin{array}{l}\text { 1. Orascar with omnivac splint for } 3 \text { weeks } \\
\text { 2. Mesh removal and implant placement at } 6 \\
\text { months after the surgery }\end{array}$ \\
\hline
\end{tabular}

DDM/rhBMP-2: Demineralized dentin matrix incorporated with rhBMP-2, Korea Tooth Bank, Korea; Ossguide: Collagen membrane, Osstem, Korea; Orascar: Attachable band-type dressing material consisted of Zinc oxide without eugenol, TBM, Korea; Retro Ti-matrix: Titanium mesh, Seum Medi, Korea.

\section{Technical Report}

This conservative protocol was initiated at right after wound dehiscence subsequent to a bone graft surgery. (1) The dehiscence was covered with a cast model made from pre-made band-type dressing material (Orascar, $0.7 \mathrm{~mm}$ thickness, TBM, Gwangju, Korea). (Figure 1A,B) (2) A cast was made from the impression with the dressing application. (3) Omnivac splint (ø $0.5 \mathrm{~mm}$ ) was fabricated from the cast (Figure 1C) (4) The dressing could be positioned appropriately on the omnivac splint by the patient (Figure 1D) and applied accurately to the dehiscence area with the splint. (Figure 1E) (5) After 5-10 min, the dressing was well maintained with adhesion to the gingiva even without the splint. (Figure 1F) The patient was instructed to add the dressing at least once a day before breakfast and to maintain oral hygiene. 

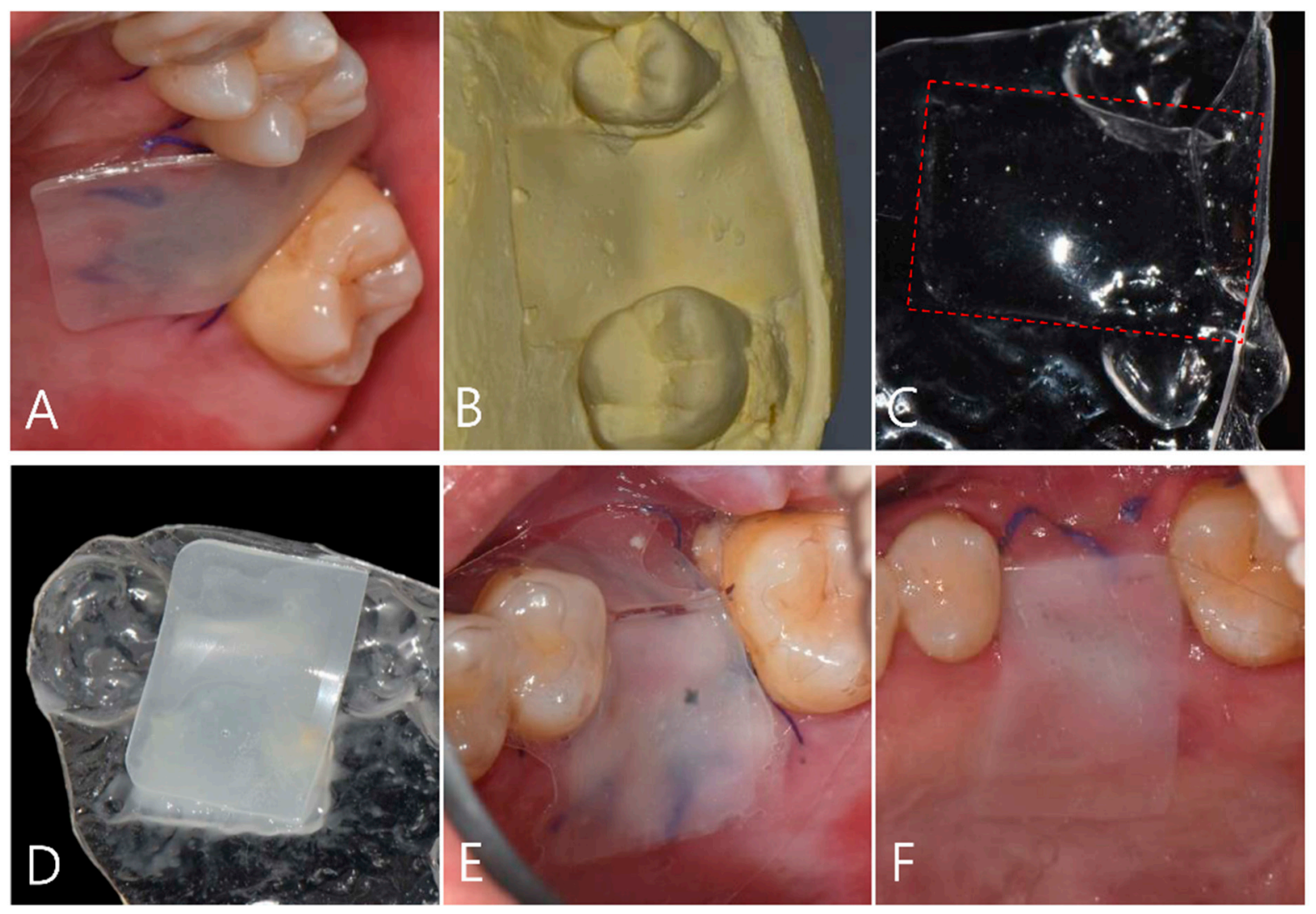

Figure 1. Conservative treatment method for wound dehiscence. (A,B). (A) cast model was made by covering the band-type dressing material. (C) An omnivec splint was fabricated from the impression with the dressing application (red dot squire). (D,E) The dressing could be applied accurately with the splint. (F) The dressing was well maintained with adhesion to the gingiva after 5-10 min of application.

\section{A Case Series}

3.1. Case \#1. Wound Dehiscence after an Autogenous Tooth Bone Graft with a Collagen Membrane

A 42-year-old male with a fracture of the left first maxillary molar underwent extraction surgery (Figure 2A,B). The extracted tooth was made as a demineralized dentin matrix incorporated with rhBMP-2 (DDM/rhBMP-2, Korea Tooth Bank, Korea) [8]. After four weeks of extraction to achieve soft tissue healing, the implant (Osstem, Korea) was placed, and a bone graft was performed simultaneously with DDM/rhBMP-2 on the maxillary sinus and guided bone regeneration (GBR) covering the collagen membrane (Ossguide, Osstem, Korea) on the palatal defect of the implant. (Figure 2C,D) Primary closure was achieved after a releasing incision. (Figure 2E) Five days after the surgery, wound dehiscence occurred on the palatal side. (Figure 2F) Using the abovementioned method (Figure 1), conservative treatment was performed by the patient.

Four weeks after surgery, secondary healing was observed without exposed the grafts (Figure 3A), and conservative treatment was stopped. The wound showed a remodeling process at 3 months after surgery. (Figure 3B) At 6 months after surgery, the prosthetic process was performed without complications. (Figure 3 C) Bony remodeling with corticocancellous complex was achieved at 12 months after surgery (Figure 3D). 

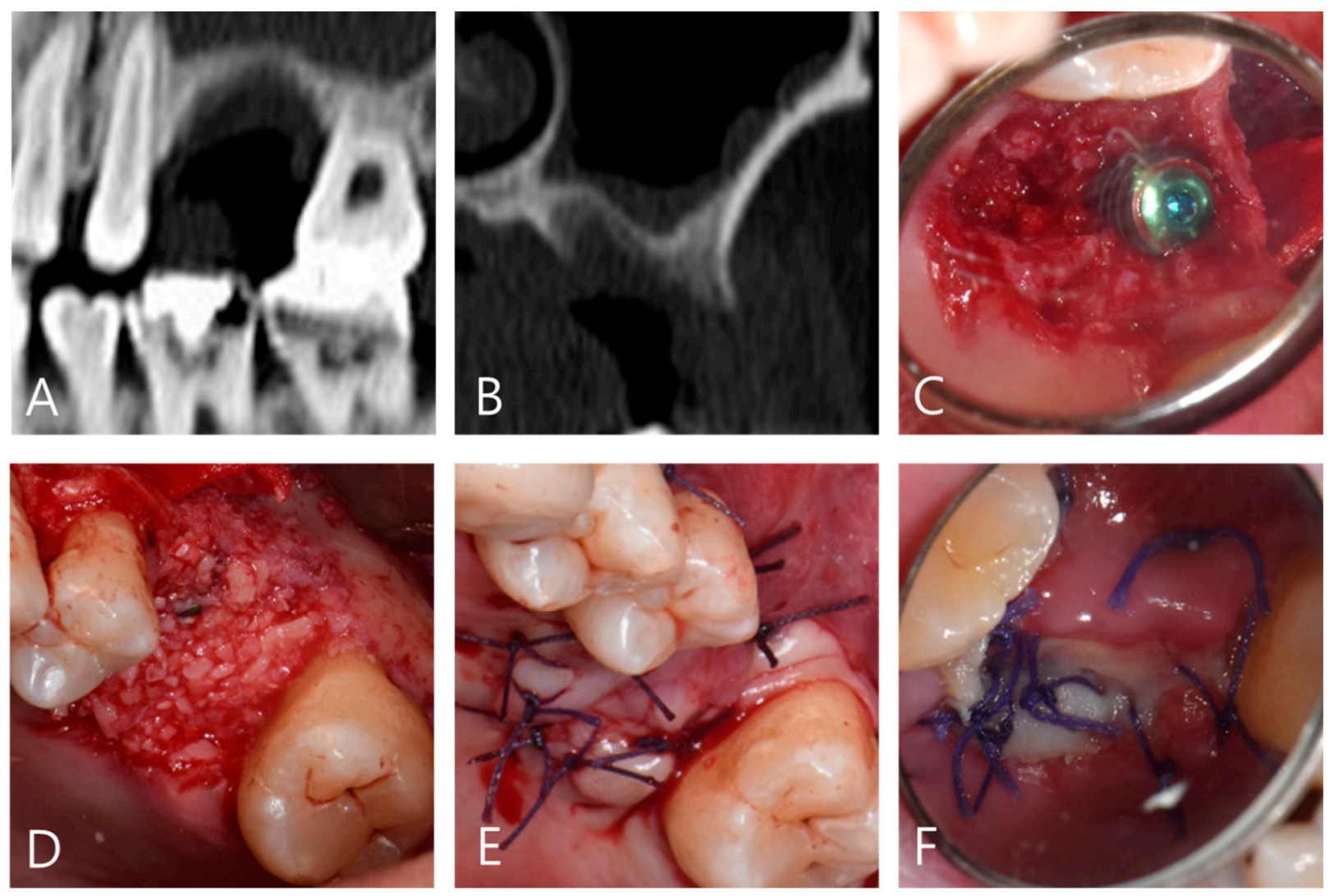

Figure 2. Wound dehiscence after an autogenous tooth bone graft with the collagen membrane of case \#1. (A,B) Preoperative radiograph on a left maxillary first molar area with insufficient residual bone for dental implant. (C) Implant was placed with a palatal defect. (D) Bone graft was performed with DDM/rhBMP-2. (E) Primary closure was achieved. (F) Wound dehiscence occurred five days after surgery.

3.2. Case \#2. Wound Dehiscence after an Autogenous Bone Graft with a Titanium Mesh and Histology Analysis with Mesh Removal at 10 Weeks Postoperatively

A 42-year-old male heavy smoker (two packs a day) lacked residual bone on the left maxillary first and second molars with maxillary sinusitis. (Figure 4A) Under general anesthesia, the extraction of hopeless teeth and bone graft were performed simultaneously to close the oroantral fistula on the left maxilla using an autogenous mandibular ramus graft with a macroporous titanium mesh (Retro Ti-matrix, Seum Medi, Korea). (Figure 4B) At postoperative 3 weeks, wound dehiscence was observed with exposed titanium mesh. (Figure 4C) Using the abovementioned method (Figure 1), conservative treatment was performed with a partial omnivac splint (Figure 4D), and the dressing material showed intimate adhesion while filling up the dehiscence defect. (Figure 4E) At 2 weeks after the conservative treatment, secondary healing was observed under the mesh. (Figure 4F). 

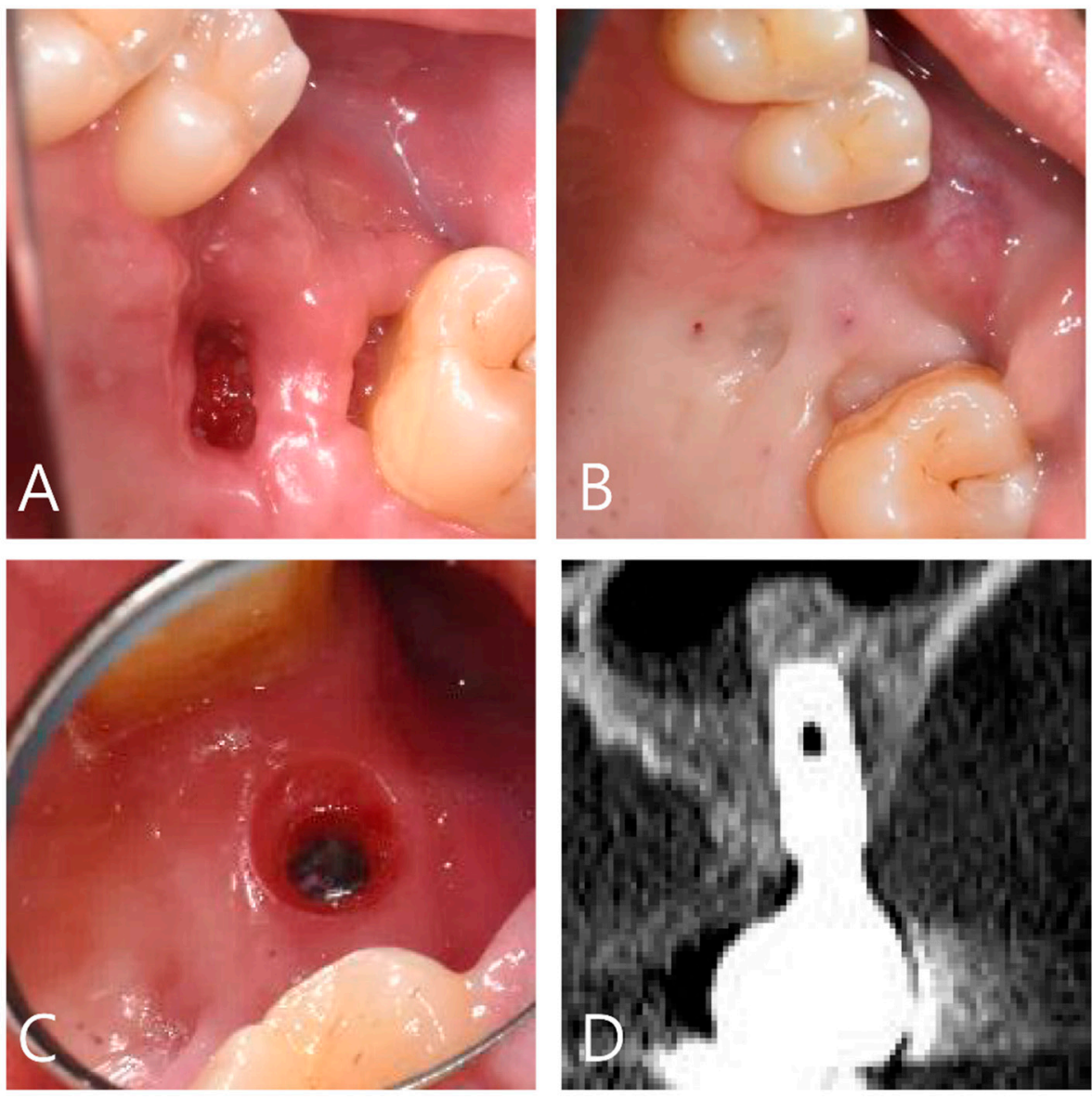

Figure 3. Clinical outcomes of the conservative treatment on case \#1. (A) After 3 weeks of the conservative treatment, secondary healing was observed in the dehiscence area. (B) At 3 months after the surgery, the soft tissue showed a remodeled-healing pattern. (C) At 6 months after the graft, the palatal gingiva was well-remodeled. (D) The palatal bone showed a cortico-cancellous complex at 12 months after the surgery.

With consideration to his smoking habit, the mesh was removed at 10 weeks after graft surgery. The bone fragments detached from the recipient site were collected during mesh removal. The histology was analyzed from the patient who consented to undergo a biopsy, microscopic examination of biopsied tissue was performed by pathologist. After decalcification and fixation, the samples were sectioned at a thickness of 5-8 $\mu \mathrm{m}$, using a microtome. The slides were stained with hematoxylin and eosin (H\&E). Histology revealed the grafted bone tissue showing some osteoblast inside the matrix (Figure 5A, arrow), and no evidence of bacterial colonization, and chronic inflammatory cells infiltration to the fibrotic stroma. (Figure 5B,C) During 12 months after the graft, dental rehabilitation was performed on the other site, and proper bone healing of the left maxilla was achieved 12 months after surgery (Figure 5D). 

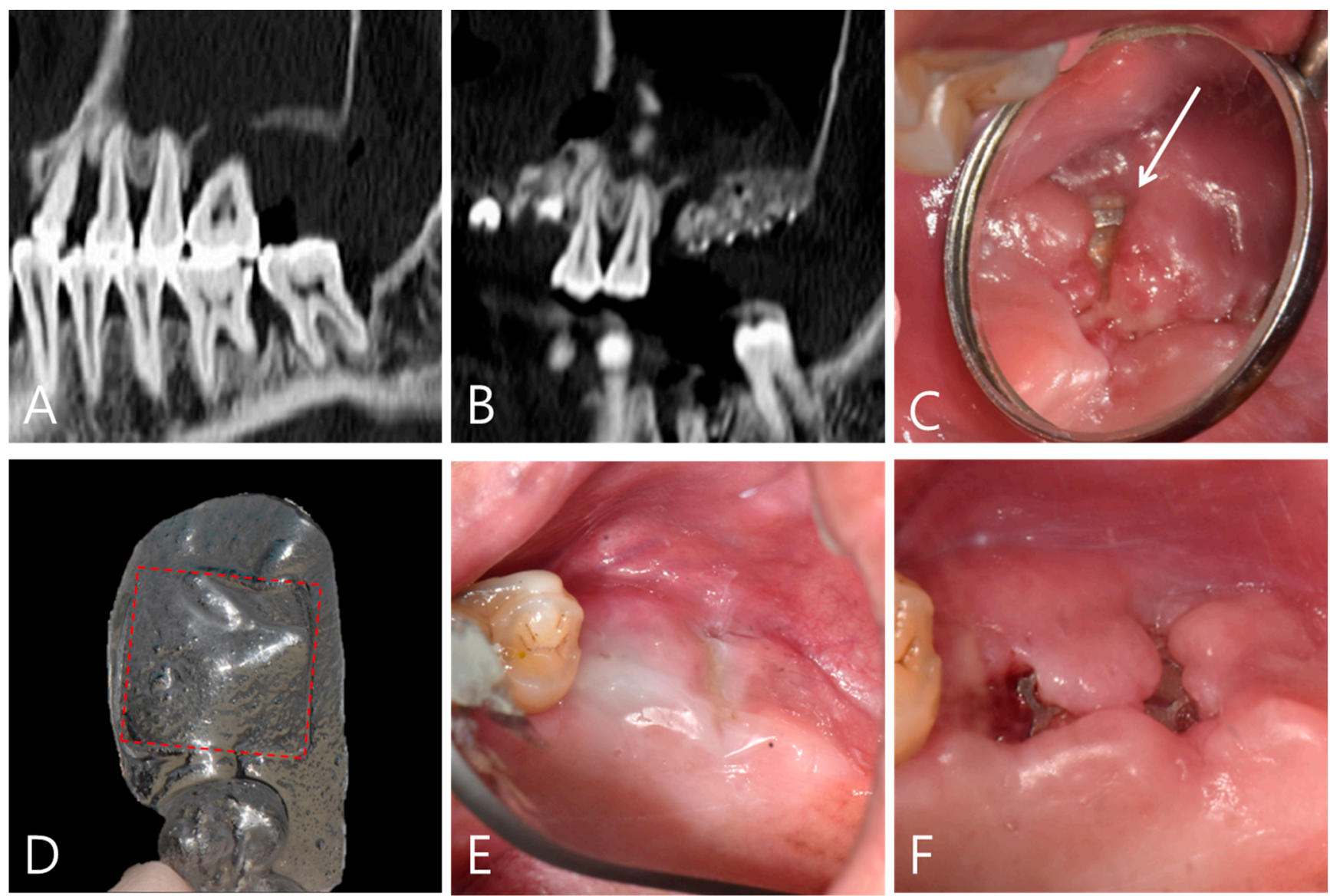

Figure 4. Wound dehiscence after an autogenous tooth bone graft with a titanium mesh of case \#2. (A) Pre-operative radiograph on the left maxillary molars showed a large defect with an oroantral fistula. (B) A bone graft was performed with autogenous ramus bone covering a titanium mesh on the left maxilla. (C) At 3 weeks after surgery, wound dehiscence occurred with an exposed titanium mesh (arrow). (D) A partial omnivac splint was fabricated from the impression with the dressing application (red dot squire). (E) The dressing material showed intimate adhesion on the dehiscence. (F) Secondary healing was observed under the mesh at two weeks after conservative treatment.

3.3. Case \#3. Wound Dehiscence after Bone Graft Mixed with Autogenous Bone and Autogenous Tooth Bone Graft

A 24-year-old male patient had a periapical lesion on the left maxillary first and second premolars and a fractured left maxillary first molar. (Figure 6A) After extracting the hopeless teeth, DDM/rhBMP-2 (Korea Tooth Bank, Korea) was fabricated [8]. At 4 weeks after the extraction, a bone graft was performed on maxillary sinus and ridge augmentation using a titanium mesh Retro Ti-matrix (Seum Medi, Korea) on DDM/rhBMP2 and autogenous ramus bone grafts. (Figure 6B) Primary closure was achieved with tension-free flap management. (Figure 6C,D) At 1 week postoperatively, the distal part of the flap exhibited a necrotic aspect during partial removal of the suture (Figure 6E), and conservative treatment was attempted as mentioned above (Figure 1). Secondary healing was achieved, and the conservative treatment was stopped after 3 weeks of conservative treatment. (Figure 6F). 

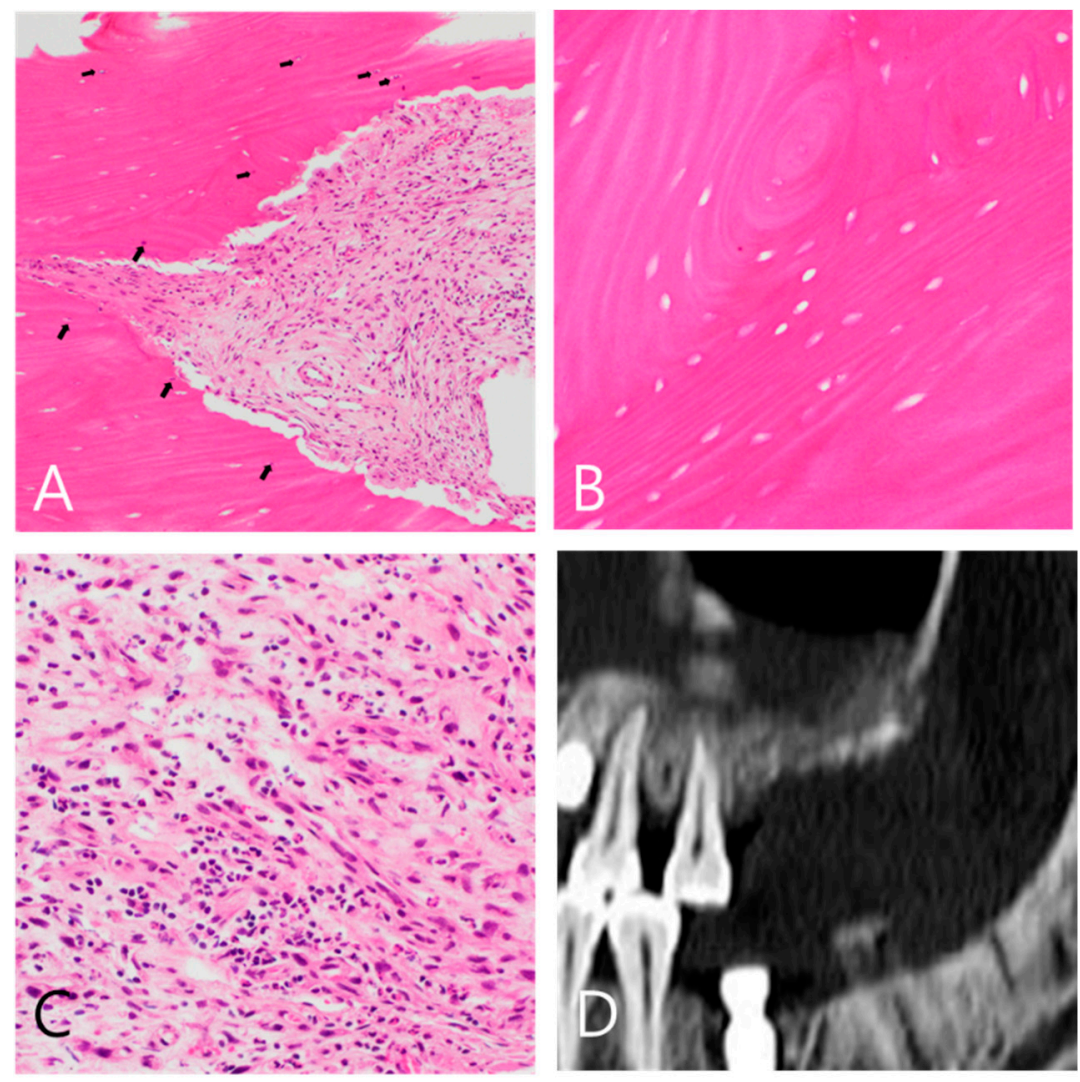

Figure 5. Histological and clinical outcomes of conservative treatment on case \#2 at 10 weeks after graft surgery. (A-C). Histological findings of the bone fragments. (A) Some osteoblasts were showed inside the grafted bone matrix. (Arrow) (B) No evidence of bacterial invasion was showed on the grafted bone fragments with a lamella pattern and empty lacunae. (C) There was only chronic inflammatory cells without evidence of bacterial invasion. (D) At 12 months after the graft, the dehiscence area showed proper bone healing without graft failure.

At 6 months after the graft, the implants were placed with titanium mesh. (Figure 7) Healed gingiva was observed with the exposed titanium mesh. (Figure 7A) On the dehiscence area, soft tissue was located under the titanium mesh dehiscence area (Figure 7B) and was connected to the buccal gingival (Figure 7C). On the other hand, acceptable bone healing was achieved, sufficient to secure the primary stability of the implant $(\varnothing 6.0 \mathrm{~mm}$, Dentium, Korea) (Figure 7D,E). 

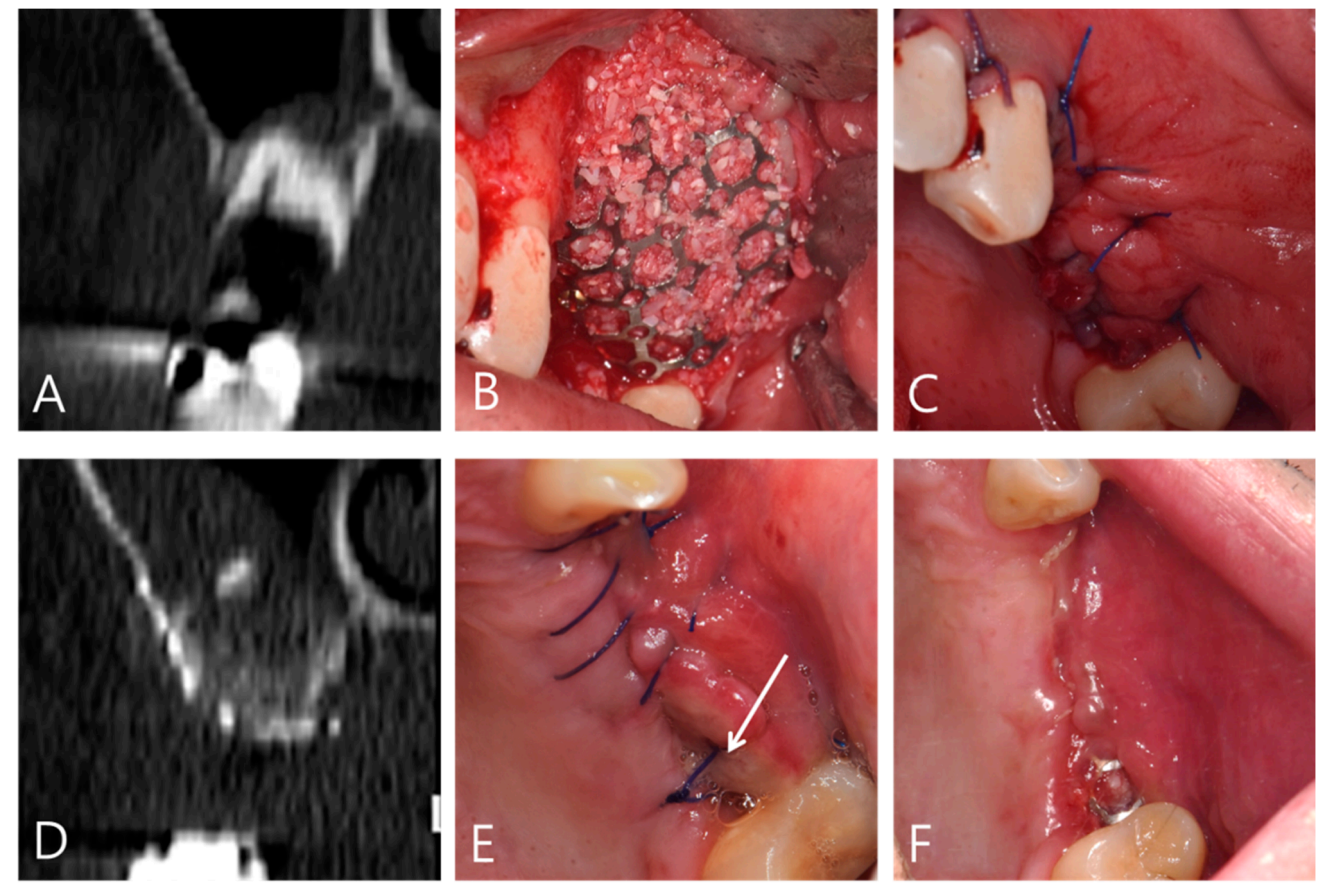

Figure 6. Wound dehiscence after autogenous tooth bone and autogenous bone graft with titanium mesh of case \#3. (A) Pre-operative radiograph on the left maxillary first molar showed a lack of residual bone. (B) A bone graft was performed using DDM/rhBMP-2 and autogenous ramus bone grafts covering the titanium mesh. (C) Primary closure was achieved with tension-free flap management. (D) Postoperative radiograph showing bone augmentation on maxillary sinus and alveolar ridge. (E) At 1 week after surgery, the distal part of the flap showed dehiscence aspects (arrow). (F) Secondary healing was observed under the mesh at 3 weeks after the conservative treatment.
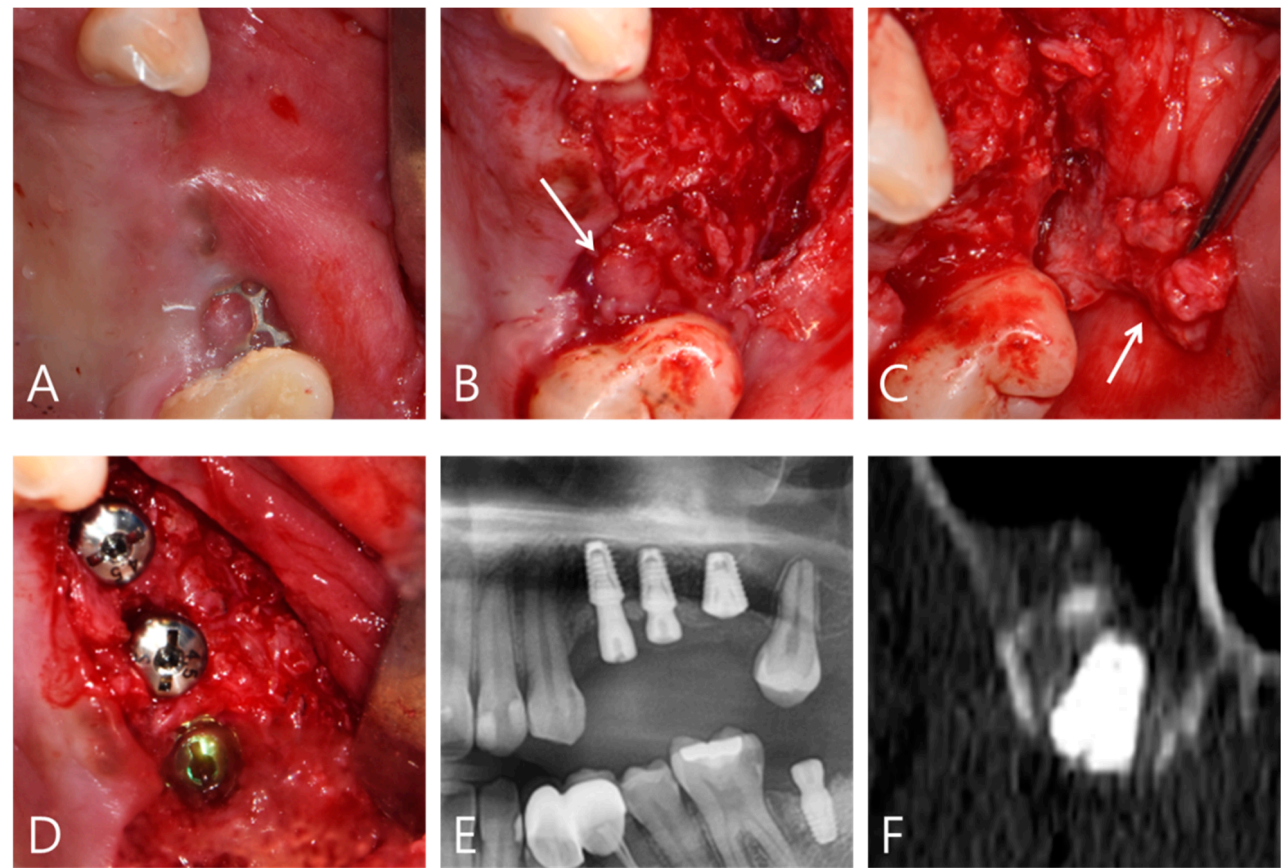

Figure 7. Clinical outcomes of the conservative treatment on case \#3. (A) At 6 months after surgery, soft tissue remodeling was achieved while the titanium mesh was exposed. (B) After mesh removal, the dehiscence area showed soft-tissue growth (arrow) under the titanium mesh. (C) The soft tissue was connected to the buccal gingiva (arrow). (D) The implants were placed with the removal of the titanium mesh on patient \#3. (E,F) The dental implant could be placed stably on the dehiscence area at 6 months after the graft. 


\section{Discussion}

The authors suggested a conservative method that allows patients to manage hygiene on their own. This method combines the advantages of the previous dressing materials, and dressing material can be applied easily with an accurate position. Orascar showed a sealing effect by adhesion with the gingiva after a few minutes of application. The dehiscence of these three patients was acceptable, and secondary healing was achieved without complications, such as bacterial infection and graft failure, within four weeks of the wound dehiscence occurrence.

Wound dehiscence can critically affect the bone graft results associated with exposed bone substitutes and membrane. In particular, the porosity of the titanium mesh can allow contamination with oral bacteria if the mesh is exposed after graft surgery. Therefore, exposure of the titanium mesh is a complication with a high risk of bacterial infection [1,9]. Regarding case \#3, secondary healing was achieved with the exposed titanium mesh using Orascar with an omnivac splint. The buccal gingiva grew into the dehiscence area under the titanium mesh. The quality of the bone graft was acceptable for a dental implant that did not require additional graft surgery.

Regarding the bone graft results, the timing of exposure is a crucial factor. Many studies reported that premature exposure (within 4 weeks after the graft) significantly affected bone healing, including total graft failure, infection, and inevitable additional graft surgery $[10,11]$. In these case reports, the dehiscence occurred within 3 weeks (Table 1). On the other hand, all cases achieved secondary healing without complications, such as infection, graft failure, and poor oral hygiene. Although some bony fragments on the dehiscence area of case \#2 showed insufficient integration with bone healing at postoperative 10 weeks, histology revealed a chronic fibrosis aspect without bacterial invasion through this conservative treatment. In addition, the other remained bone grafts had well-integrated and healed during 12 months after the bone graft. (Figure 5D).

Zinc oxide without eugenol (COE-PAK ${ }^{\circledR}$, Coe Laboratories Inc., Chicago, IL, USA) is one of the most famous oral dressing materials, and has high stability and fixation on the oral mucosa, but it is difficult for the patient to reattach the dressing and manage oral hygiene while maintaining the dressing. Neither zinc oxide nor eugenol (Orascar ${ }^{\circledR}$, TBM, Gwangju, Korea), used in this case series, was easy to manage because it could form an adhesive film in response to the saliva. In addition, its main composition of ethyl cellulose is widely used to prepare pharmaceutical dosage forms, which is non-toxic, stable, compressible and inert polymer [12]. To be available for the dehiscence on the bone graft, however, it should be applied to the appropriate position to be sealed and protected from oral bacteria. Therefore, the omnivac splint with an engraved Orascar was used as a guide to the exact position by the patient. Through this technique, the patient could maintain their oral hygiene and reported no discomfort for food intake.

The bone substitutes of autogenous bone and DDM/rhBMP-2, used in this research, were the graft material, which might induce secondary healing and resist infection [13]. Therefore, it is unclear if the validation of this conservative treatment will be effective for other bone substitutes without osteoinductivity, such as alloplastic and xenografts. Although this method could prevent infection and allow secondary healing, the amount of bone healing was insufficient. Further research will be needed to develop a dressing material that contains a growth factor to promote soft and hard tissue regeneration.

\section{Conclusions}

Although oral dressing materials have developed as attachable property, self-manage with the dressing material is still difficult by patient himself. This conservative treatment, using the attachable dressing material, allowed the patient to maintain their oral hygiene using an omnivec splint. Moreover, this protocol can achieve the secondary healing without infection on the wound dehiscence after ridge augmentation with osteoinductive bone substitutes. 
Author Contributions: conceptualization, J.-K.K. and D.H.L.; methodology J.-K.K. and D.H.L.; software, T.K. and I.-W.C.; validation, Y.K.J.; investigation, Y.K.J. and Y.-S.C.; resources, J.-K.K. and D.H.L.; data curation, T.K. and I.-W.C.; writing—original draft preparation, J.-K.K.; writing-review and editing, Y.K.J.; visualization, J.-K.K.; supervision, D.H.L.; project administration, J.-K.K. and D.H.L. All authors have read and agreed to the published version of the manuscript.

Funding: This paper received no external funding.

Institutional Review Board Statement: This case series was conducted according to the guidelines of the Declaration of Helsinki and was approved by the Institutional Review Board (No. AFCH-20IRB-041) on 2 October 2021.

Informed Consent Statement: Patient consent was waived due to the retrospective study design.

Data Availability Statement: Data are contained within the article.

Conflicts of Interest: The authors reported no conflicts of interest related to this research.

\section{References}

1. Kim, Y.-K.; Ku, J.-K. Guided bone regeneration. J. Korean Assoc. Oral Maxillofac. Surg. 2020, 46, 361-366. [CrossRef] [PubMed]

2. Sakkas, A.; Wilde, F.; Heufelder, M.; Winter, K.; Schramm, A. Autogenous bone grafts in oral implantology-Is it still a "gold standard"? A consecutive review of 279 patients with 456 clinical procedures. Int. J. Implant. Dent. 2017, 3, 23. [CrossRef] [PubMed]

3. Um, I.-W.; Ku, J.-K.; Kim, Y.-K.; Lee, B.-K.; Leem, D.H. Histological Review of Demineralized Dentin Matrix as a Carrier of rhBMP-2. Tissue Eng. Part B Rev. 2020, 26, 284-293. [CrossRef] [PubMed]

4. Cucchi, A.; Vignudelli, E.; Napolitano, A.; Marchetti, C.; Corinaldesi, G. Evaluation of complication rates and vertical bone gain after guided bone regeneration with non-resorbable membranes versus titanium meshes and resorbable membranes. A randomized clinical trial. Clin. Implant. Dent. Relat. Res. 2017, 19, 821-832. [CrossRef] [PubMed]

5. Fontana, F.; Maschera, E.; Rocchietta, I.; Simion, M. Clinical classification of complications in guided bone regeneration procedures by means of a nonresorbable membrane. Int. J. Periodontics Restor. Dent. 2011, 31, 265-273.

6. Baghani, Z.; Kadkhodazadeh, M. Periodontal dressing: A review article. J. Dent. Res. Dent. Clin. Dent. Prospect. 2013, 7, 183-191.

7. Kadkhodazadeh, M.; Baghani, Z.; Torshabi, M.; Basirat, B. In Vitro Comparison of Biological Effects of Coe-Pak and Reso-Pac Periodontal Dressings. J. Oral Maxillofac. Res. 2017, 8, e3. [CrossRef] [PubMed]

8. Um, I.-W.; Jun, S.-H.; Yun, P.-Y.; Kim, Y.-K. Histological Comparison of Autogenous and Allogenic Demineralized Dentin Matrix Loaded with Recombinant Human Bone Morphogenetic Protein-2 for Alveolar Bone Repair: A Preliminary Report. J. Hard Tissue Biol. 2017, 26, 417-424. [CrossRef]

9. Rasia-dal Polo, M.; Poli, P.P.; Rancitelli, D.; Beretta, M.; Maiorana, C. Alveolar ridge reconstruction with titanium meshes: A systematic review of the literature. Med. Oral Patol. Oral Cir. Bucal 2014, 19, e639-e646. [CrossRef] [PubMed]

10. Machtei, E.E. The effect of membrane exposure on the outcome of regenerative procedures in humans: A meta-analysis. $J$. Periodontol. 2001, 72, 512-516. [CrossRef] [PubMed]

11. Moses, O.; Pitaru, S.; Artzi, Z.; Nemcovsky, C.E. Healing of dehiscence-type defects in implants placed together with different barrier membranes: A comparative clinical study. Clin. Oral Implant. Res. 2005, 16, 210-219. [CrossRef] [PubMed]

12. Crowley, M.M.; Schroeder, B.; Fredersdorf, A.; Obara, S.; Talarico, M.; Kucera, S.; McGinity, J.W. Physicochemical properties and mechanism of drug release from ethyl cellulose matrix tablets prepared by direct compression and hot-melt extrusion. Int. J. Pharm. 2004, 269, 509-522. [CrossRef] [PubMed]

13. Um, I.-W.; Ku, J.-K.; Kim, Y.-M.; Yun, P.-Y.; Chang, N.-H.; Kim, Y.-K.; Choi, Y. Allogeneic Demineralized Dentin Matrix Graft for Guided Bone Regeneration in Dental Implants. Appl. Sci. 2020, 10, 4661. [CrossRef] 